\title{
A proposal for determination of dimensional tolerances and adjustments considering the concepts from Design for Dimensional Control (DDC)
}

\section{Guilherme Akio Oi*, Robert Eduardo Cooper Ordoñez}

\begin{abstract}
The growth of quality requirements of products in the industry stimulated the methodical study of dimensional tolerances, always considering the cost factor. Tools that belong to Design for Dimensional Control (DDC) try to solve this subject. However, even with the existence of these concepts, it is noted that there is an inadequacy of the solution of this problem in the industry. This research intends to contribute to a solution of this question by doing a literature review, finding some variables, which were inserted in the product lifecycle, based on the model called Product Development Process (PDP). Furthermore, a method was elaborated for application of the control of dimensional variation, in order to provide an accessible tool.
\end{abstract}

\section{Key words:}

Dimensional control, Dimensional variation, Non-quality cost

\section{Introduction}

The incessant transformations in the industry caused the growth of quality requirements of products, enabling the development of manufacturing processes and stimulating the methodical study of dimensional tolerances. Therefore, the Design for Dimensional Control (DDC) ${ }^{1}$ emerges, which consists of the dimensional variation management during the project, manufacturing and functionality, without the need of additional refining procedures in the shop floor, in manufacturing and assembly processes.

Although this is an important subject in the industry, it was noted that there is a gap, without much content about this topic. Based on the few researches found, twelve variables were obtained, which were included into the product lifecycle, according to the model called Product Development Process $(\mathrm{PDP})^{2}$, which consists of an approach that covers every process from business related to products and allow companies to control every information of their products during the lifecycle, from the conception to the phase out.

Lastly, a solution was elaborated, based on the concept of loss-function of Genichi Taguchi ${ }^{3}$, for the purpose of simulating the non-quality cost of a product produced and assisting manufacturers to lower their production costs.

\section{Results and Discussion}

From the literature review, twelve variables were obtained, which are presented in Chart 1. These variables were included in the PDP model and it was noted that the variables were most related to the phases of Conceptual Design and Detailed Design, inside of the Development macro phase.

Chart 1. Variables obtained from the literature review

\begin{tabular}{|c|l|}
\hline Number & \multicolumn{1}{c|}{ Defined variables } \\
\hline 1 & Tolerances of components and assemblies \\
\hline 2 & Precision of manufacturing processes \\
\hline 3 & Sequence of manufacturing processes \\
\hline 4 & Sequence of assembly processes \\
\hline 5 & Machines available \\
\hline 6 & Change of scope \\
\hline 7 & Demand for components \\
\hline 8 & $\begin{array}{l}\text { Type of communication used (Technical drawing, } \\
\text { software) }\end{array}$ \\
\hline 9 & Available time to finish the project \\
\hline
\end{tabular}

\begin{tabular}{|c|l|}
\hline 10 & Total costs of the product/available resources \\
\hline 11 & $\begin{array}{l}\text { Number of manufacturing and assembly } \\
\text { operations needed }\end{array}$ \\
\hline 12 & Geometry complexity of the components \\
\hline
\end{tabular}

The last phase consisted in the development of a methodology, presented in Image 1. This method was developed in MATLAB code to facilitate its application.

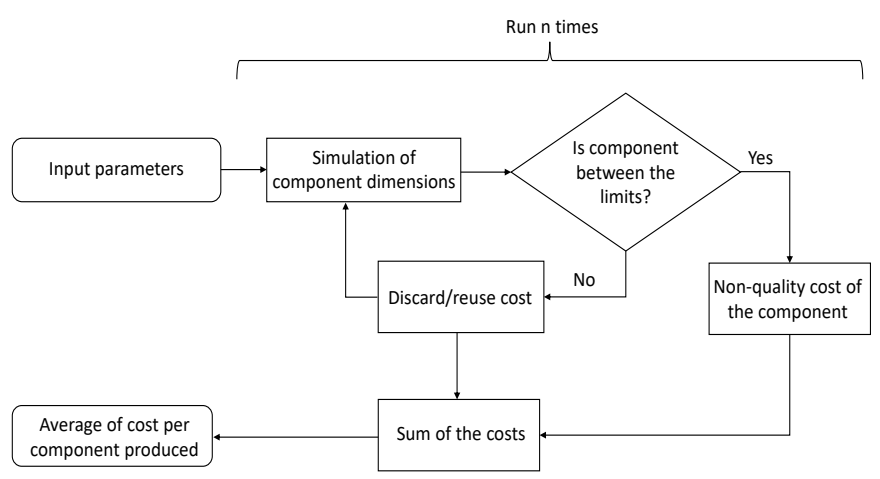

Image 1. Flow chart of the method elaborated.

This tool allows comparing the costs of non-quality with manufacturing costs, in order to reduce the overall production cost.

\section{Conclusions}

It is concluded that the method presented can assist manufacturers to find the optimum value of minimum cost, with low need of resources, becoming an accessible tool.

\section{Acknowledgement}

This project was funded by $C N P q$ through the Institutional Scientific Initiation Scholarship Program (PIBIC), being supported by PRP (Pró-Reitoria de Pesquisa) of the University of Campinas (UNICAMP).

\footnotetext{
${ }^{1}$ Huang, G.Q. Design for X: Concurrent Engineering Imperatives. London UK: Editora Chapman \& Hall, 1996.

${ }^{2}$ Fonseca, F. E. A.; Rozenfeld, H. Medição de desempenho para a gestão do ciclo de vida de produtos: uma revisão sistemática da literatura. Revista Produção Online. Florianópolis, SC, v.12, n.1, p. 159-184, jan./mar 2012.

3 Taguchi, G.; Chowdhury, S.; Wu, Y. Taguchi's Quality Engineering Handbook. Wiley; 2004. 1696p.
} 